\title{
Complement Bb Measurement
}

National Cancer Institute

\section{Source}

National Cancer Institute. Complement Bb Measurement. NCI Thesaurus. Code C80172.

The determination of the amount of complement $\mathrm{Bb}$ present in a sample. 